\title{
ChemComm
}

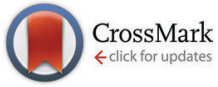

Cite this: Chem. Commun., 2015, 51, 13702

Received 10th July 2015

Accepted 23rd July 2015

DOI: $10.1039 / c 5 c c 05730 b$

www.rsc.org/chemcomm

\section{Thermochromic and solvatochromic properties of Lindqvist polyoxometalates $\dagger$}

\author{
S. Herrmann, ${ }^{a}$ J. T. Margraf, ${ }^{b}$ T. Clark ${ }^{b}$ and C. Streb ${ }^{{ }^{a}}$
}

The thermochromic and solvatochromic properties of Lindqvist metal oxide clusters $\left[\mathrm{V}_{x} \mathrm{M}_{6-x} \mathrm{O}_{19}\right]^{n-}(x=0,1,2, M=M o, W)$ are reported. The cluster anions show pronounced changes of their electronic structure depending on their chemical environment (e.g. solvent polarity, temperature). These are rationalized using experimental and theoretical methods. A combined density functional theory and ${ }^{51} \mathrm{~V}$-NMR study suggests that temperature-dependent changes in the structural dynamics of the metal oxide framework are the underlying cause for the observed thermochromism. The results might open new avenues for the design of molecular optical sensors.

Molecular metal oxides, so-called polyoxometalates (POMs) are functional materials where the chemical and physical properties can be optimized on the atomic level. ${ }^{1}$ This is achieved by changing the cluster architecture or by chemical modification of the cluster shell. ${ }^{1 a, 2}$ Using these approaches, versatile molecular materials for catalysis, ${ }^{3}$ energy conversion and storage,${ }^{4}$ molecular magnetism ${ }^{5}$ and molecular electronics ${ }^{6}$ have been developed. Of particular current interest is the design of molecular materials which show responsiveness to external stimuli, e.g. changes in their physical or chemical environment. ${ }^{7}$ This gives access to functional compounds for the design of adaptive sensor systems, ${ }^{8}$ thermo- and photochromic devices ${ }^{9}$ or molecular switches. ${ }^{10}$ However, to tune the properties of POMs towards specific applications, a better understanding of the underlying electronic properties as well as their response to stimuli is required. ${ }^{11}$

One particularly intriguing example in the field of thermochromic, stimuli-responsive materials has been reported by Cronin et al. The authors showed that sulfite-functionalized Dawson anions $\beta$ - $\left[\mathrm{Mo}_{18} \mathrm{O}_{54}\left(\mathrm{SO}_{3}\right)_{2}\right]^{4-}$ feature significant and reversible colour changes, gradually transforming upon heating from pale

\footnotetext{
${ }^{a}$ Institute of Inorganic Chemistry I, Ulm University, Albert-Einstein-Allee 11, 89081 Ulm, Germany. E-mail: carsten.streb@uni-ulm.de; Web: www.strebgroup.net ${ }^{b}$ Department Chemistry and Pharmacy, Computer-Chemistry-Center,

Friedrich-Alexander-University Erlangen-Nuremberg, Nägelsbachstrasse 25, 91052 Erlangen, Germany

$\dagger$ Electronic supplementary information (ESI) available: Synthetic, analytical, spectroscopic and computational details. See DOI: 10.1039/c5cc05730b
}

yellow $(77 \mathrm{~K})$ to deep red $(500 \mathrm{~K}) \cdot{ }^{9 a, d}$ Interestingly, these thermochromic features could also be triggered by an external stimulus: when the clusters were deposited on conducting substrates (e.g. gold), significant changes of the electronic cluster structure were observed. ${ }^{9 b}$ These changes were assigned to an internal redox-reaction, leading to oxidation of the sulfur centres and reduction of two molybdate centres from $\mathrm{Mo}^{\mathrm{VI}}$ to $\mathrm{Mo}^{\mathrm{V}}{ }^{12}$

Recently, we have begun to investigate how electronic cluster properties can be tuned by incorporation of heterometals ${ }^{13}$ into the cluster shell. ${ }^{14}$ To this end, a series of isostructural Lindqvist anions $\left[\mathrm{M}_{6} \mathrm{O}_{19}\right]^{2-}\left(\mathrm{M}=\mathrm{Mo}^{\mathrm{VI}}, \mathrm{W}^{\mathrm{VI}}\right)^{15}$ were synthesized ${ }^{14}$ and we could show that the visible-light photoactivity of the clusters can be optimized by incorporation of vanadium(v) ions, giving the cluster anions $\left[\mathrm{V}_{x} \mathrm{M}_{6-x} \mathrm{O}_{19}\right]^{(2+x)-}\left(x=0,1,2 ; \mathrm{M}=\mathrm{Mo}^{\mathrm{VI}}, \mathrm{W}^{\mathrm{VI}}\right) .{ }^{14 b, e, f}$ As the fundamental absorption properties of the clusters are vital for the understanding of their photoreactivity, we investigated the temperature-dependent and solvent-dependent changes in absorption for the Lindqvist cluster family.

Here we report the observation of pronounced thermochromism and solvatochromism of Lindqvist anions $\left[\mathrm{V}_{x} \mathrm{M}_{6-x} \mathrm{O}_{19}\right]^{(2+x)-}(x=0$, 1,$\left.2 ; \mathrm{M}=\mathrm{Mo}^{\mathrm{VI}}, \mathrm{W}^{\mathrm{VI}}\right) \cdot{ }^{14 b, e}$ A mechanistic understanding of their behaviour is provided based on experimental and computational data and a synthetic strategy is illustrated which makes the clusters accessible in virtually any organic solvent. ${ }^{16}$

The principal absorption features of the Lindqvist anions are ligand to metal charge-transfer (LMCT) transitions where electrons are promoted from oxo-centred orbitals to empty metal-centred orbitals. ${ }^{17}$ These transitions are strongly affected by the electronic environment, e.g. the polarity of the solvent. ${ }^{18}$ However, in polyoxometalates, pronounced solvatochromism is rarely observed as traditional POM salts are only soluble in polar solvents such as $\mathrm{H}_{2} \mathrm{O}, \mathrm{CH}_{3} \mathrm{CN}$, DMSO, etc. Protocols to transfer POMs into various other solvents have been developed and are typically based on cation exchange by phase transfer. ${ }^{19}$ We have recently shown that POM ionic liquids (POM-ILs) are also well suited to deliver POMs into non-polar solvents. ${ }^{16 a}$

In the current report, we have used this strategy to exchange the original $\mathrm{NMe}_{4}{ }^{+}$counter cation of the Lindqvist anion for the 


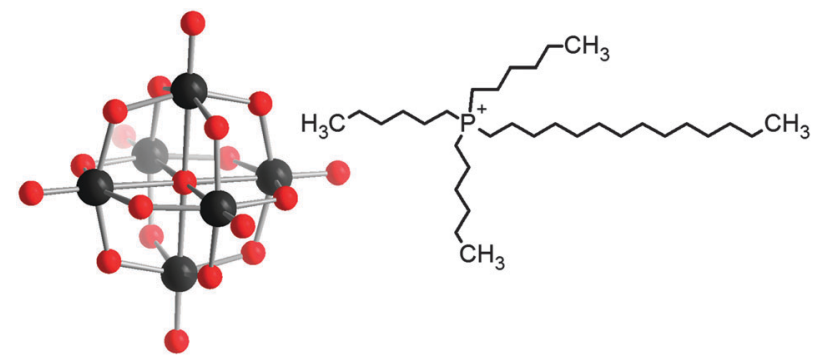

Fig. 1 Illustration of the Lindqvist anion $\left[\mathrm{M}_{6} \mathrm{O}_{19}\right]^{n-}$ (left) and the tetraalkylphosphonium cation $\left({ }^{6,6,6,14} \mathrm{P}^{+}\right)$used in this study (right). Colour scheme: M (i.e. V, Mo, W): black, O: red.

bulky cation trihexyl(tetradecyl)phosphonium $\left(=^{6,6,6,14} \mathrm{P}^{+}\right)$as reported previously. ${ }^{20}$ Cation metathesis was performed on several Lindqvist anions $\left[\mathrm{V}_{x} \mathrm{M}_{6-x} \mathrm{O}_{19}\right]^{(2+x)-}\left(x=0,1,2, \mathrm{M}=\mathrm{Mo}^{\mathrm{VI}}, \mathrm{W}^{\mathrm{VI}}\right.$, see Fig. 1 and ESI $\dagger$ ). However, as similar properties were observed in all cases, this report is focused on the cis-isomer of the prototype $\left({ }^{6,6,6,14} \mathrm{P}\right)_{4}\left[\mathrm{~V}_{2} \mathrm{~W}_{4} \mathrm{O}_{19}\right](\mathbf{1})$. Product purity and cluster stability were confirmed by elemental analysis, FT-IR, UV-Vis and NMR spectroscopy.

The solvatochromic properties of $\mathbf{1}$ were studied using UV-vis spectroscopy based on solutions of $\mathbf{1}$ in organic solvents with varying polarity, see Fig. 2. The spectra feature a characteristic LMCT absorption band in the region of $350 \mathrm{~nm}$ to $500 \mathrm{~nm}$ which is strongly solvent dependent: for polar protic solvents (e.g. methanol),
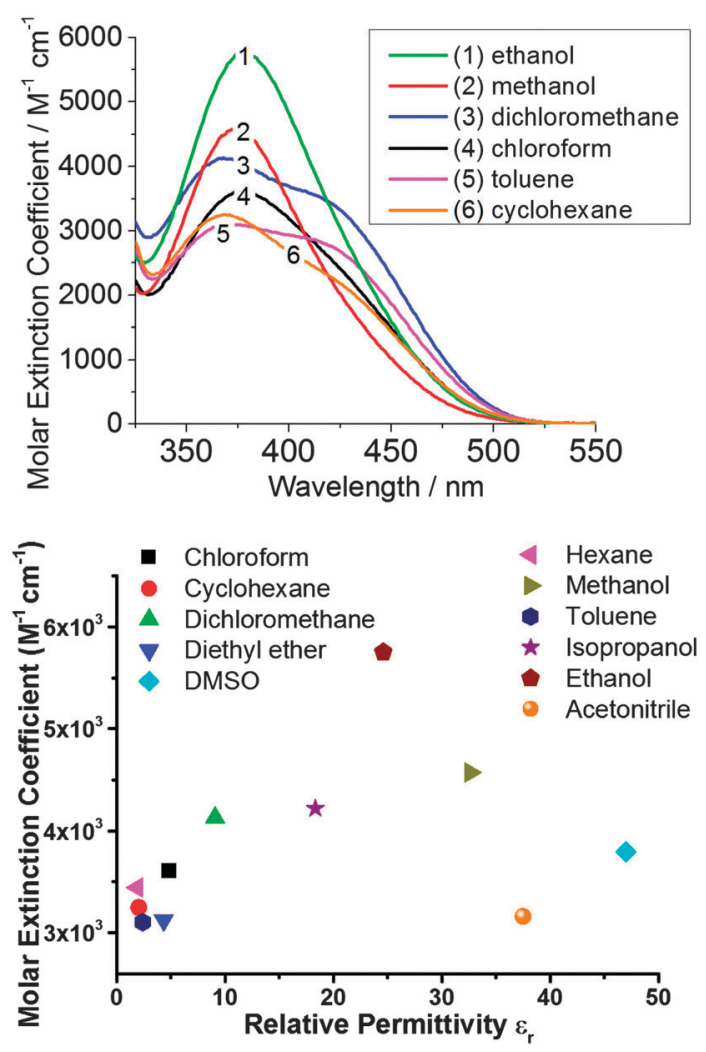

Fig. 2 Top: UV-vis spectra of 1 at room temperature in polar and nonpolar solvents. Bottom: Plot of the observed molar extinction coefficients of 1 as a function of solvent relative permittivity. only one peak was observed $\left(\lambda_{\max , 1} \sim 375 \mathrm{~nm}\right)$. In contrast, nonprotic solvents (both polar and non-polar) give two peaks with peak maxima at approximately $\lambda_{\max , 1} \sim 370 \mathrm{~nm}$ and $\lambda_{\max , 2} \sim 415 \mathrm{~nm}$. Calculations indicate that this behaviour could be attributed to hydrogen-bonding interactions between the cluster anion and the protic solvents (see ESI $\dagger$ ).

When investigating the effect of solvent polarity on the molar extinction coefficient of $\mathbf{1}$ (Fig. 2b), it was found that maximum extinction coefficients are observed for solvents with relative permittivity $\varepsilon_{\mathrm{r}}$ in the range of $\varepsilon_{\mathrm{r}}=20-35$, e.g. $\varepsilon$ (ethanol, $378 \mathrm{~nm}) c a .5750 \mathrm{M}^{-1} \mathrm{~cm}^{-1}$. Solvents with $\varepsilon_{\mathrm{r}}<20$ and $\varepsilon_{\mathrm{r}}>35$ result in generally lower extinction coefficients (e.g. $\varepsilon$ (toluene, $371 \mathrm{~nm}$ ) ca. $3100 \mathrm{M}^{-1} \mathrm{~cm}^{-1}$; $\left.\varepsilon(\mathrm{MeCN}, 369 \mathrm{~nm}) c a .3160 \mathrm{M}^{-1} \mathrm{~cm}^{-1}\right)$, see ESI. $\dagger$ When comparing the influence of the solvent Gutmann acceptor number on the extinction coefficient, it was observed that high acceptor numbers are generally associated with high molar extinction coefficients, see ESI. $\dagger$ The observed trends could be useful when developing POM-based photocatalysts where optimized light-absorbance is essential. ${ }^{17}$

In preliminary studies, a striking thermochromic behaviour of $\left[\mathrm{V}_{2} \mathrm{~W}_{4} \mathrm{O}_{19}\right]^{4-}$ was visually observed, see Fig. 3. Upon cooling 1 to $77 \mathrm{~K}$ in liquid nitrogen, a colour change from intense orange ( $300 \mathrm{~K}$ ) to bright yellow $(77 \mathrm{~K})$ was found. The colour change is reversible and is observed both in solution (e.g. diethyl ether) and in the solid state. Further, the colour change is independent of the cluster counter-ion: similar thermochromism was observed for the ${ }^{6,6,6,14} \mathrm{P}^{+}, n \mathrm{Bu}_{4} \mathrm{~N}^{+}$and $\mathrm{K}^{+}$salts. Subsequent studies showed that this behaviour is observed for other Mo- and W-based Lindqvist clusters also, for details see ESI. $\dagger$

To gain further insight into the electronic structure of the Lindqvist anions and their temperature-dependent changes, densityfunctional theory (DFT) based molecular dynamics simulations were performed (see ESI†). These calculations allowed a temperature dependent analysis of the HOMO-LUMO orbital energies,

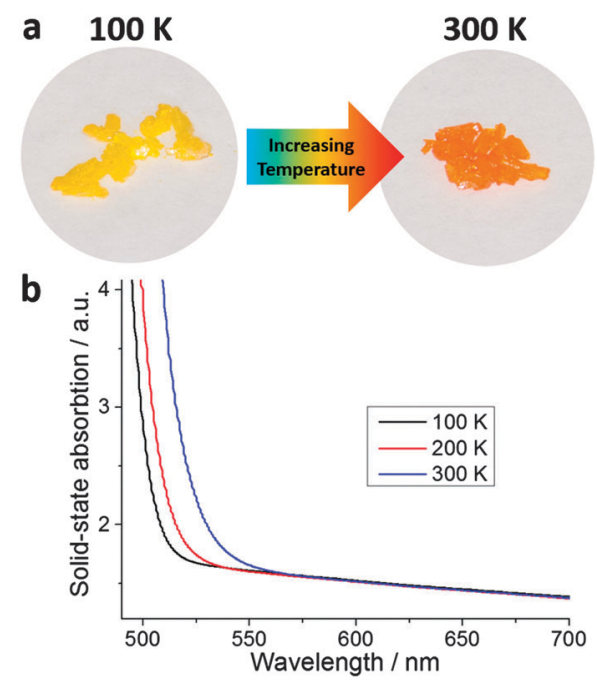

Fig. 3 (a) Photographs of crystals of $\left(n \mathrm{nu}_{4} \mathrm{~N}\right)_{4}\left[\mathrm{~V}_{2} \mathrm{~W}_{4} \mathrm{O}_{19}\right]$ taken at $\sim 100 \mathrm{~K}$ (left) and at $\sim 300 \mathrm{~K}$ (right); (b) solid-state UV-vis spectrum of 1 between 100 and $300 \mathrm{~K}$, showing the bathochromic shift of the absorption onset with increasing temperature. 

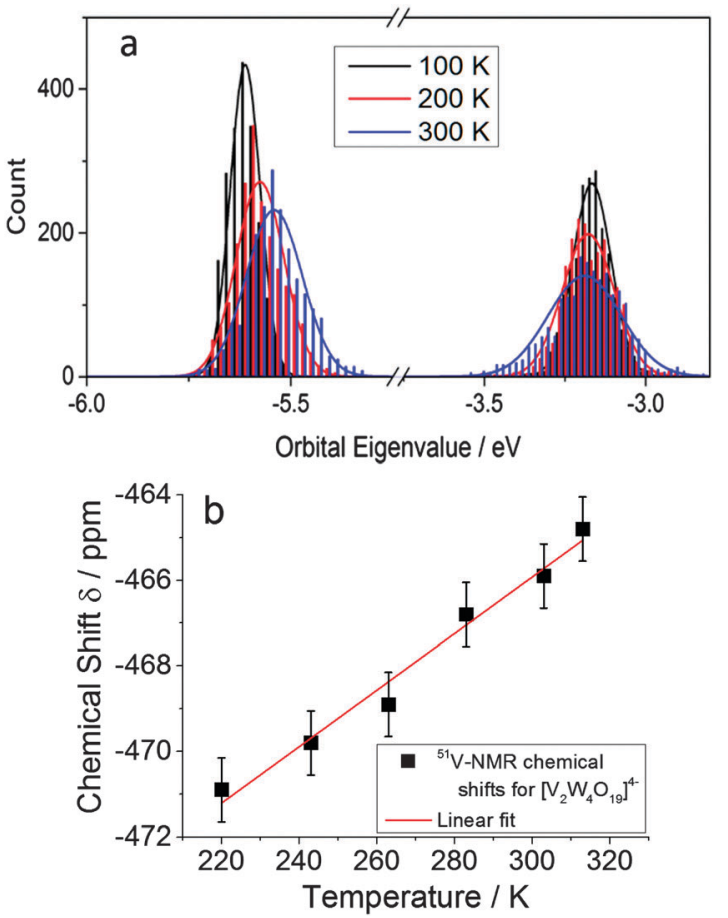

Fig. 4 (a) Temperature-dependent histograms of $\mathrm{HOMO}$ and LUMO eigenvalues of $\left[\mathrm{V}_{2} \mathrm{~W}_{4} \mathrm{O}_{19}\right]^{4-}$ collected from 2 ps molecular dynamic (MD) computations at 100-300 K. (b) Temperature-dependent change of the chemical shift $\delta$ of the $V$ centres in $\mathbf{1}$ observed by ${ }^{51} \mathrm{~V}$-NMR spectroscopy (solvent: acetone-D6).

which showed that with increasing temperature the HOMOLUMO gap decreases, see Fig. 4a. Due to the increased structural dynamics of the metal-oxide framework, the distribution of orbital eigenvalues is also broadened. Semi-empirical configuration interaction calculations on the related $\left[\mathrm{VMo}_{5} \mathrm{O}_{19}\right]^{3-}$ cluster show that the temperature induced decrease in HOMO-LUMO gap is accompanied by decreased excitation energies, confirming the observed bathochromic absorption shift upon heating (see ESI $\dagger$ ). The structural changes upon heating are fully expected as the thermal energy introduced allows the system to occupy energetically higher-lying vibrational states resulting in the observed structural distortions of the metal oxide framework which in turn cause the changes in the HOMO-LUMO gap described.

The change in physical and electronic structure in $\mathbf{1}$ was probed experimentally by temperature-dependent ${ }^{51} \mathrm{~V}$-NMR-spectroscopy. In previous studies, it was shown that the ${ }^{51} \mathrm{~V}$-NMR shift of vanadium centres in Lindqvist anions can be used to probe protonation state, ${ }^{21}$ isomerism ${ }^{21}$ and solid-state counterion effects. ${ }^{22}$ In the examined temperature range (220-313 K, in acetone-D6) significant changes of the chemical shift $\delta$ of the V-related signal were observed, suggesting a change of the chemical environment due to changes in the structural dynamics of the metal oxide framework, see Fig. 4b. These experimental findings were further supported by DFT calculations, which showed similar trends for the temperature-dependent change in chemical shift $\delta$ for the ${ }^{51} \mathrm{~V}$-NMR signals, see ESI. $\dagger$

In summary, we report, for the first time, the solvatochromic and thermochromic properties of a family of homo- and heterometallic Lindqvist anions. Pronounced effects of the electronic environment of the cluster anion and the structural dynamics of the cluster on their ligand-to-metal charge-transfer properties are observed, suggesting that they can be used as molecular probes to gain insight into different chemical environments. Future research will target the development of chemical sensors with a particular focus on harsh chemical environments where the high cluster stability could be advantageous.

The Fonds der Chemischen Industrie is gratefully acknowledged for a PhD (S.H.) fellowship. J.T.M. acknowledges a PhD fellowship by the Beilstein Foundation. Prof. Takuya Shiga and Prof. Hiroki Oshio (Tsukuba University) are acknowledged for solid-state UV spectroscopy. This work was financially supported by Ulm University and Friedrich-Alexander-University Erlangen-Nuremberg.

\section{Notes and references}

1 (a) Special POM-themed issue: L. Cronin and A. Müller (guest eds.), Chem. Soc. Rev., 2012, 41, 7325-7648; (b) M. T. Pope, Y. Jeannin and M. Fournier, Heteropoly and isopoly oxometalates, Springer-Verlag, Berlin, 1983.

2 Special POM issue: C. L. Hill (guest ed.), Chem. Rev., 1998, 98.1-300.

3 (a) B. B. Sarma, I. Efremenko and R. Neumann, J. Am. Chem. Soc., 2015, 137, 5916-5922; (b) K. Sugahara, N. Satake, K. Kamata, T. Nakajima and N. Mizuno, Angew. Chem., Int. Ed., 2014, 53, 13248-13252.

4 (a) H. J. Lv, Y. V. Geletii, C. C. Zhao, J. W. Vickers, G. B. Zhu, Z. Luo, J. Song, T. Q. Lian, D. G. Musaev and C. L. Hill, Chem. Soc. Rev., 2012, 41, 7572-7589; (b) A. Sartorel, M. Bonchio, S. Campagna and F. Scandola, Chem. Soc. Rev., 2013, 42, 2262-2280.

5 (a) J. M. Clemente-Juan, E. Coronado and A. Gaita-Arino, Chem. Soc. Rev., 2012, 41, 7464-7478; (b) A. Barbour, R. D. Luttrell, J. Choi, J. L. Musfeldt, D. Zipse, N. S. Dalal, D. W. Boukhvalov, V. V. Dobrovitski, M. I. Katsnelson, A. I. Lichtenstein, B. N. Harmon and P. Kögerler, Phys. Rev. B: Condens. Matter Mater. Phys., 2006, 74, 014411.

6 C. Busche, L. Vila-Nadal, J. Yan, H. N. Miras, D.-L. Long, V. P. Georgiev, A. Asenov, R. H. Pedersen, N. Gadegaard, M. M. Mirza, D. J. Paul, J. M. Poblet and L. Cronin, Nature, 2014, 515, 545-549.

7 (a) J. Kong, N. R. Franklin, C. Zhou, M. G. Chapline, S. Peng, K. Cho and H. Dai, Science, 2000, 287, 622-625; (b) M. Ammam, J. Mater. Chem. A, 2013, 1, 6291-6312; (c) A. Seliverstov and C. Streb, Chem. Commun., 2014, 50, 1827-1829.

8 (a) S. Herrmann, C. Ritchie and C. Streb, Dalton Trans., 2015, 44, 7092-7104; (b) Y. Ji, L. Huang, J. Hu, C. Streb and Y.-F. Song, Energy Environ. Sci., 2015, 8, 776-789.

9 (a) D. L. Long, P. Kögerler and L. Cronin, Angew. Chem., Int. Ed., 2004, 43, 1817-1820; (b) C. Fleming, D.-L. Long, N. McMillan, J. Johnston, N. Bovet, V. Dhanak, N. Gadegaard, P. Kögerler, L. Cronin and M. Kadodwala, Nat. Nanotechnol., 2008, 3, 229-233; (c) P. He, B. Xu, H. Liu, S. He, F. Saleem and X. Wang, Sci. Rep., 2013, 3, 1833; (d) S. Liu, H. Möhwald, D. Volkmer and D. G. Kurth, Langmuir, 2006, 22, 1949-1951.

10 (a) K. Suzuki, R. Sato and N. Mizuno, Chem. Sci., 2013, 4, 596-600; (b) J. Lehmann, A. Gaita-Arinjo, E. Coronado and D. Loss, Nat. Nanotechnol., 2007, 2, 312-317.

11 (a) J. A. Fernandez, X. Lopez, C. Bo, C. de Graaf, E. J. Baerends and J. M. Poblet, J. Am. Chem. Soc., 2007, 129, 12244-12253; (b) X. Lopez, J. J. Carbo, C. Bo and J. M. Poblet, Chem. Soc. Rev., 2012, 41, 7537-7571; (c) I. M. Mbomekalle, X. Lopez, J. M. Poblet, F. Secheresse, B. Keita and L. Nadjo, Inorg. Chem., 2010, 49, 7001-7006.

12 R. Tsunashima, D.-L. Long, T. Endo, S.-I. Noro, T. Akutagawa, T. Nakamura, R. Q. Cabrera, P. F. McMillan, P. Kogerler and L. Cronin, Phys. Chem. Chem. Phys., 2011, 13, 7295-7297.

13 (a) R. J. Errington, L. Coyle, P. S. Middleton, C. J. Murphy, W. Clegg and R. W. Harrington, J. Cluster Sci., 2010, 21, 503-514; (b) R. J. Errington, G. Harle, W. Clegg and R. W. Harrington, Eur. J. Inorg. Chem., 2009, 5240-5246; (c) R. J. Errington, S. S. Petkar, P. S. Middleton and W. McFarlane, J. Am. Chem. Soc., 2007, 129, 12181-12196; (d) R. J. Errington, S. S. Petkar, B. R. Horrocks, 
A. Houlton, L. H. Lie and S. N. Patole, Angew. Chem., Int. Ed., 2005, 44, 1254-1257; (e) M. Filowitz, R. K. C. Ho, W. G. Klemperer and W. Shum, Inorg. Chem., 1979, 18, 93-103.

14 (a) J. Tucher and C. Streb, Beilstein J. Nanotechnol., 2014, 5, 711-716; (b) J. Tucher, S. Schlicht, F. Kollhoff and C. Streb, Dalton Trans., 2014, 43, 17029-17033; (c) J. Forster, B. Rösner, R. H. Fink, L. C. Nye, I. Ivanovic-Burmazovic, K. Kastner, J. Tucher and C. Streb, Chem. Sci., 2013, 4, 418-424; (d) J. Tucher, L. C. Nye, I. Ivanovic-Burmazovic, A. Notarnicola and C. Streb, Chem. - Eur. J., 2012, 18, 10949-10953; (e) J. Tucher, Y. L. Wu, L. C. Nye, I. Ivanovic-Burmazovic, M. M. Khusniyarov and C. Streb, Dalton Trans., 2012, 41, 9938-9943; $(f)$ A. Seliverstov, J. Forster, M. Heiland, J. Unfried and C. Streb, Chem. Commun., 2014, 50, 7840-7843; $(g)$ K. Kastner, J. Margraf, T. Clark and C. Streb, Chem.-Eur. J., 2014, 20, 12269-12273; (h) K. Kastner, J. Forster, H. Ida, G. N. Newton, H. Oshio and C. Streb, Chem.-Eur. J., 2015, 21, 7686-7689; (i) J. Tucher, K. Peuntinger, J. T. Margraf, T. Clark, D. M. Guldi and C. Streb, Chem.-Eur. J., 2015, 21, 8716-8719.

15 (a) M. Nyman, Dalton Trans., 2011, 40, 8049-8058; (b) T. M. Anderson, M. A. Rodriguez, F. Bonhomme, J. N. Bixler, T. M. Alama and M. Nyman, Dalton Trans., 2007, 4517-4522.
16 (a) S. Herrmann, M. Kostrzewa, A. Wierschem and C. Streb, Angew. Chem., Int. Ed., 2014, 53, 13596-13599; (b) S. H. Szczepankiewicz, C. M. Ippolito, B. P. Santora, T. J. Van de Ven, G. A. Ippolito, L. Fronckowiak, F. Wiatrowski, T. Power and M. Kozik, Inorg. Chem., 1998, 37, 4344-4352.

17 C. Streb, Dalton Trans., 2012, 41, 1651-1659.

18 C. Reichardt, Chem. Rev., 1994, 94, 2319-2358.

19 (a) F. Corigliano and S. Di Pasquale, Inorg. Chim. Acta, 1975, 12, 99-101; (b) F. Corigliano and S. Di Pasquale, Inorg. Chim. Acta, 1975, 12, 102-104; (c) D. E. Katsoulis and M. T. Pope, J. Am. Chem. Soc., 1984, 106, 2737-2738.

20 (a) P. G. Rickert, M. R. Antonio, M. A. Firestone, K.-A. Kubatko, T. Szreder, J. F. Wishart and M. L. Dietz, J. Phys. Chem. B, 2007, 111, 4685-4692; (b) P. G. Rickert, M. R. Antonio, M. A. Firestone, K.-A. Kubatko, T. Szreder, J. F. Wishart and M. L. Dietz, Dalton Trans., 2007, 529-531.

21 (a) W. G. Klemperer and W. Shum, J. Am. Chem. Soc., 1978, 100, 4891-4893; (b) M. A. Leparulo-Loftus and M. T. Pope, Inorg. Chem., 1987, 26, 2112-2120.

22 W. Huang, L. Todaro, L. C. Francesconi and T. Polenova, J. Am. Chem. Soc., 2003, 125, 5928-5938. 